\title{
PENGEMBANGAN E-MODUL BERBASIS STEM (SCIENCE, TECHNOLOGY, ENGINEERING AND MATHEMATIC) PADA MATERI FLUIDA STATIS DAN FLUIDADINAMIS MENGGUNAKAN KIVOSFT FLIPBOOK MAKER
}

\author{
Rita Arnila ${ }^{1}$ Sri Purwaningsih ${ }^{2}$, Nehru ${ }^{3 *}$ \\ $1 *, 2,3$ Physics Education, Universitas Jambi, Indonesia \\ * Corresponding Author. E-mail: ${ }^{1}$ rhitame11216@gmail.com, ${ }^{2}$ sripurwaningsih@unja.ac.id \\ , ${ }^{3}$ nehruunja@gmail.com
}

\begin{abstract}
Abstrak
Tujuan dari penelitian ini aadalah untuk mengembangkan modul elektronik dengan menggunakan software Kivosft Flipbook Maker pada materi fluida statis dan fluida dinamis. Jenis penelitian ini adalah penelitian dan pengembangan dengan menggunakan model yang telah di lakukan oleh Marshall, J.C Julie, S \& Robert dan Rusdi. Ada lima tahapan pengembangan yaitu analisis masalah dan kebutuhan. analisis masalah dan kebutuhan, Tinjauan literature, desain produk, validitas, dan uji coba praktisi. Penelitian ini hanya sebatas tahap validitas. Pada penelitian ini juga menggunakan pendekatan STEM sains (sicence), teknologi (technology), rekayasa (engineering), and matematika (mathemmatics). Modul elektronik yang telah dikembangakan memiliki format exeyang dapat dijalankan pada PC/lapatop. Modul elektronik ini telah divalidasi dan dinyatakan valid dengan ratarata skor ahli materi sebesar 3,9 tergolong dalam kategori sangat baik. Dan rata-rata skor ahli media sebesar 3,4 tergolong dalam kategori yang sangat baik. Keungggulan pengembangan modul elektronik menggunakan software Kivosft Flipbook Maker yaitu bahasanya mudah dimengerti, didalamnya terdapat video yang bisa membuat siswa belajar secara mandiri dan bisa diakses secara online, serta tampilan gambar yang menarik. Adapun kekurangannya yaitu belum bisa sepenuhnya diakses dengan smartphone dan harus menggunakan bantuan flash player versi terbaru dari aplikasi tersebut untuk membukanya.
\end{abstract}

Kata Kunci: STEM, modul elektronik, Kivosft Flipbook Maker

\begin{abstract}
The purpose of the study this is to develop a module electronics by using software Kivosft Flipbook Maker in the material fluid static and fluid dynamic Type of research this is a research and development by using model that has been in done by Marshall, JC Julie,S \& Robert and Rusdi. There are five stages development namely analysis of problems and needs. Analysis of problems and needs, review literature, the of products, validity, and test try practitioner. This research is only limited to the validity stage. No research is also using approaches STEM science (science), technology (technology), engineering (engineering), andmathematics ( mathemmatics).The electronic module that has been developed has an . exe format that can be run on a PC/laptop . This electronic module has been validated and declared valid with an average score of 3,9 material experts classified in a category. And the average score of expert media amounted to 3,4 classified in a category that is very good. excellence development of module electronics using software kvisoft flipbook maker is the language easy to understand, in which there is a video that can make student
\end{abstract}


Jurnal Edumaspul, 5 (1), Year 2021- 552

(Rita Arnila, Sri Purwaningsih, Nehru)

learn to be independent and can be accessed by online, as well as display images are interesting. As for the short comings that have not been able to fully accessed by Smartphone and should use the help of flash player version of the latest of the application are to open it.

Keywords: STEM, module electronics ,Kivosft Flipbook Maker

\section{Pendahuluan}

Menurut Sujana (2019) Pendidikan merupakan proses yang berkelanjutan dan tak pernah berakhir (never ending proces), sehingga dapat menghasilkan suatu kualitas yang berkesinambungan, yang ditujukan pada perwujudan sosok manusia untuk masa depan, dan berakar pada nilai-nilai budaya bangsa serta Pancasila. Pendidikan harus menumbuh kembangkan nilai-nilai filosofis dan budaya bangsa secara utuh dan menyuluruh. Sehingga perlu adanya kajian yang lebih mendalam terhadap pendidikan, maka dari itu pendidikan mulai dipandang secara filsafat yang merujuk pada kejelasan atas landasan pendidikan itu sendiri. Pendidikan tentu saja tidak hanya mengedepankan penanaman semata melainkan penanaman karakter bangsa yang dimaksud juga telah diatur didalam undangundang negara Indonesia. Hal ini dilakukan guna memberikan arah terhadap pelaksanaan dan perkembangan.

Pembelajaran pada hakikatnya merupakan proses interaksi dan komunikasi antara guru dengan siswa. Proses pembelajaran memegang peranan penting dalam mendukung hasil dan tujuan belajar siswa, sehingga kualitas dari proses pembelajaran sangat perlu untuk diperhatikan. Terdapat banyak faktor yang dapat mempengaruhi kualitas proses pembelajaran baik secara internal maupun eksternal. Salah satu faktor yang mempengaruhi kualitas pembelajaran adalah tersedianya bahan ajar yang memadai. Kurangnya bahan ajar tentu sangat mempengaruhi suatu kualitas pembelajaran.

Tersedianya bahan ajar yang memadai sangat penting untuk siswa dalam pembelajaran. Bahan ajar yang sesuai tuntutan kurikulum dan kebutuhan siswa akan membantu membangun komunikasi yang efektif antara guru dan siswa sehingga proses pembelajaran bersifat lebih interaktif. Selain itu, tersedianya bahan ajar yang memadai dapat menunjang kemandirian siswa dalam belajar. Salah satu bahan ajar yang sering digunakan dalam pembelajaran adalah buku teks. Namun meskipun dapat dijumpai dengan mudah, buku teks belum sepenuhnya menunjang pemahaman siswa terhadap materi yang sedang dipelajari. Buku teks hanya berfokus pada penyajian materi sehingga mengabaikan motivasi dan aktivitas dari penggunanya. Buku teks juga menyebabkan siswa kurang termotivasi untuk belajar mandiri, berarti keberadaan buku teks tidak mampu untuk meningkatkan motivasi anak untuk belajar. Hal ini berdampak pada rendahnya hasil belajar siswa. Jadi disini masih diperlukan pengembangan modul yang menarik agar terjadi peningkatan hasil belajar siswa (Rahmi,2014).

Menurut Maulana (2014) Bahan ajar adalah bahan atau materi pelajaran yang disusun secara lengkap dan sistematis berdasarkan prinsip-prinsip pembelajaran yang digunakan guru dan siswa dalam proses pembelajaran. Bahan ajar bersifat sistematis, artinya disusun secara berurut sehingga memudahkan siswa untuk belajar. Beberapa jenis bahan ajar terdiri atas non cetak dan cetak. Bahan ajar non cetak meliputi bahan ajar dengar (audio), bahan ajar pandang dengar (audio visual), dan bahan ajar multimedia interaktif (interactive teaching material). Sedangkan bahan ajar cetak yang sering dijumpai di antaranya berupa handout, buku,brosur, lembar kerja siswa, dan modul. Jadi bahan ajar adalah bahan ataupun materi yang disusun secara lengkap untuk memudahkan siswa dalam memahami suatu proses pembelajaran.

Pembuatan urutan penyajian materi pelajaran yang mengacu pada upaya untuk menunjukkan kepada siswa keterkaitan antara fakta, konsep, prosedur dan prinsip 
yang terkandung dalam materi pembelajaran tersebut. Jadi modul adalah salah satu bahan ajar yang dikemas secara sistematis dan menarik sehingga mudah dipahami secaramandiri.

Dengan pemberian bahan ajar berupa modul, siswa dapat belajar mandiri tanpa harus dibantu oleh guru. Siswa yang memiliki kecepatan belajar yang rendah dapat berkali-kali mempelajari setiap kegiatan belajar tanpa terbatas oleh waktu, sedangkan siswa yangkecepatanbelajarnyatinggiakanlebihcepa tmempelajarisatukompetensi dasar.

Menurut Rosa (2015) Kurikulum 2013 menekankan pada aktivitas siswa, sehingga pengembangan modul dibuat sebagai salah satu pendukung dari keterlaksanaan kurikulum 2013, dimana guru dituntut untuk membimbing siswa untuk lebih aktif dalam pembelajaran. Dengan pengembangan modul siswa akan berperan aktif dan tertarik sehingga motivasi belajarnya akan meningkat, begitu pula dengan hasil belajarnya. Proses pembelajaran idealnya dapat melibatkan siswa secara aktif.

Menurut Sirate (2017) modul adalah bahan ajar yang dirancang secara sistematis berdasarkan kurikulum tertentu dan dikemas dalam bentuk satuan pembelajaran terkecil dan memungkinkan dipelajari secara mandiri dalam satuan waktu tertentu agar siswa menguasai kompetensi yang diajarkan. Modul juga merupakan satuan program belajar mengajar yang terkecil, yang dipelajari oleh siswa sendiri secara perseorangan atau diajarkan oleh siswa kepada dirinya sendiri (selfinstructional). Modul adalah suatu cara pengorganisasian materi pelajaran yang memperhatikan fungsi pendidikan. Strategi pengorganisasian materi pembelajaran mengandung squencing yang mengacu pada pembuatan urutan penyajian materi pelajaran.

Menurut Taufik (2017) Berkembangnya ilmu pengetahuan dan teknologi yang semakin pesat di masa sekarang ini dan dimana saat ini zaman semakin modern sangat nyata dampaknya. Dapat dilihat dari teknologiteknologi canggih yang membantu kita di berbagai aspek kehidupan. Kemutakhiran teknologi yang kita miliki dalam membantu kehidupan sehari-hari mengindikasikan bahwa hal tersebut tidak lepas dari berkembangnya kemampuan manusia di bidang ilmu pengetahuan. Hal inilah menjadi alasan dibutuhkannya pengembangan kegiatan pembelajaran yang dapat mencakup sains (sicence), teknologi (technology), rekayasa (engineering), dan matematika (mathemmatics) yang biasa disingkat dengan sebutan STEM. Pendidikan STEM saat ini memainkan peran penting dalam pendidikan modern bagi negara untuk tetap mengikuti persaingan dalam ekonomi global. Dengan penerapan pendidikan STEM dapat mengembangkan proses berpikir ilmiah siswa terhadap permasalahan yang harus dipecahkan, STEM juga baik untuk perkembangan anak di masa depan. Siswa akan terlatih untuk berpikir logis, kreatif, dan disiplin.hal ini lah yang membuat e-modul yang digunakan diharapkan mampu meningkatkan motivasi siswa dan lebih mudah dipahami. Memasuki era digital, modul pembelajaran yang dulunya berbasis cetak berinovasi ke dalam bentuk digital (e-modul) yang lebih praktis. Emodul dibuat dengan menggunakan software yang setiap halaman menjadi layaknya sebuah modul elektronik.

Menurut Nikita, dkk (2018) Modul elektronik adalah sebuah bentuk penyajian bahan belajar mandiri yang disusun secara sistematis ke dalam unit pembelajaran terkecil yang bertujuan untuk mencapai tujuan pembelajaran tertentu yang disajikan ke dalam format elektronik (Gunawan, 2010). Modul elektronik merupakan penggabungan istilah modul dalam bentuk bahan ajar elektronik.

Modul elektronik adalah modul yang disajikan dalam bentuk elektronik. Menurut Sugianto (2013), Modul elektronik (e-modul) adalah sebuah bentuk penyajian bahan belajar mandiri yang disusun secara sistematis ke dalam unit pembelajaran terkecil untuk mencapai tujuan pembelajaran tertentu yang disajikan ke dalam format elektronik yang di dalamnya terdapat animasi, audio, navigasi yang membuat pengguna lebih interaktif dengan program. Modul elektronik pada dasarnya dalam struktur penulisannya mengadaptasi format, karakteristik, 
dan bagian-bagian yang terdapat pada modul lima tahapan pengembangan yaitu analisis cetak pada umumnya.

\section{Metode}

Penelitian ini merupakan penelitian pengembangan. Produk yang dihasilkan dari penelitian ini berupa sebuah e-modul dengan materi fluida statis dan fluida dinamis dengan menggunakan pendekatan STEM (Science, Technology, Engineering, And Mathematics ) dengan menggunakan Software Kvisoft Flipbook Maker. Model Pada penelitian ini juga menggunakan model yang telah di lakukan oleh Marshall, J.C Julie, S \& Robert dan Rusdi. Ada lima tahapan pengembangan yaitu analisis masalah dan kebutuhan. analisis masalah dan kebutuhan, injauan literature, desain produk, validitas, uji coba praktisi. Anmun di dalam penelitian ini hanya sampai pada tahap validasi oleh para ahli.instrumenpengumpulan data dalam penelitian ini berupa lembar validasi ahli dan validasi media serta hasil observasi yang dilakukan. Data kuatitatif dianalisis menggunakan skal likert, pilihan jawaban yang disediakan sangat baik, baik, tidak baik, dan sangat tidak baik. Jawaban diisi dengan memberikan skor 1 s.d 4 pada setiap pertanyaan, klasifikasi skor skala likert dapaat dilihat pada Tabel 1.

Tabel 1 Klasifikasi Skor

\begin{tabular}{|l|l|}
\hline Interval skor & Kategori Skor \\
\hline $1,00-1,75$ & $\begin{array}{l}\text { Sangat tidak } \\
\text { baik }\end{array}$ \\
\hline $1,76-2,50$ & Tidak baik \\
\hline $2,51-3,25$ & Baik \\
\hline $3,26-4,00$ & Sangat baik \\
\hline
\end{tabular}

\section{Hasil dan pembahasan}

Hasil dari penelitian pengembangan ini adalah modul elektronik yang dibuat dengan menggunakan Software Kvisoft Flipbook Maker pada materi fluida statis dan fluida dinamis. Pada penelitian ini menggunakan pendekatan STEM sains (sicence), teknologi (technology), rekayasa (engineering), and matematika (mathemmatics). Pada penelitian ini juga menggunakan model yang telah di lakukan oleh Marshall, J.C Julie, S \& Robert dan Rusdi. Ada masalah dan kebutuhan. analisis masalah dan kebutuhan, injauan literature, desain produk, validitas, uji coba praktisi. Namun penelitian pengembangan ini hanya sampai tahap uji validasi terhadap produk yang dikembangakan. Tahap pertama yang dilakukan peneliti yaitu mealakukan analisis kebutuhan. Tahap analisis adalah tahap awal dalam mengembangkan modul elektronik ini. Analisis dilakukan untuk mengidentifikasi fakta yang ada dalam proses pembelajaran dan merekomendasikan solusi yang sesuai dengan kondisi saat dilakukannya observasi awal.

Analisis kebutuhan dalam pengembangan suatu poduk adalah hal yang sangat penting untuk memastikan produk yang dikembangakan sesuai dengan kebutuhan pengguna. Analisis kebutuhan terdiri dari analisis materi dan analisis literature. Analisis materi digunakan sebagai dasar dalam pengembangan modul elektronik. Dalam pemgembangan modul elektronik ini peneliti mengambil materi fluida statis dan fluida dinamis di kelas XI. Dalam mengambil materi tersebut peneliti menganalisi $\mathrm{KI}$ KD dan indiaktor berdasarkan permendikbud No 24 tahun 2016. Berdasarkan hasil dari analisis tersebut peneliti memberikan solusi dengan melakukan kajian penelitian lanjutan, yaitu berupa pengembangan modul elektronika yang memuat aspek dari tuntutan $\mathrm{KI}, \mathrm{KD}$ dan indikator materi fluida statis dan fluida dinamis.

Analisis literatur dilakukan dengan cara mengumpulkan semua informasi yang di cari dari berbagai sumber yang dpat digunakan sebagai pedoman dalam mendesain dan mengembangkan produk. Pada tahap ini peneliti melengkapi kajian pustaka yang berkaitan dengan penelitian dan menganalisis penelitian yang relevan untuk mendukung proses pengembangan produk yang peneliti kembangkan.

Tahap selanjutnya peneliti melakukan desain modul elektronik. Adapun bentuk desain awal aplikasi sebelum melalui tahap perbaikan dan validasi oleh para ahli adalah sebagai berikut: 
a. Sampul e-modul

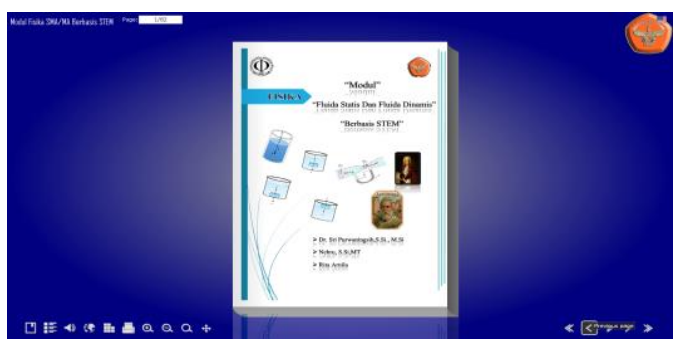

Ini merupakan tampila awal pengembangan modul elektronik yang didesign oleh peneliti.

b. Tampilan daftar isi

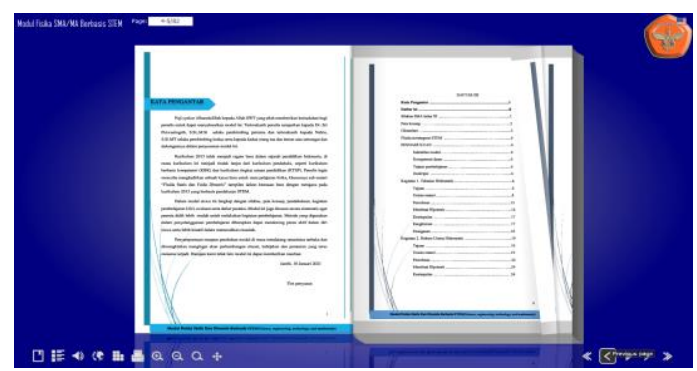

Halaman ini menampilkan tampilan kata pengantar dan daftar sisi yang ada didalam emodul tersebut.

c. Tampilan halaman percobaan

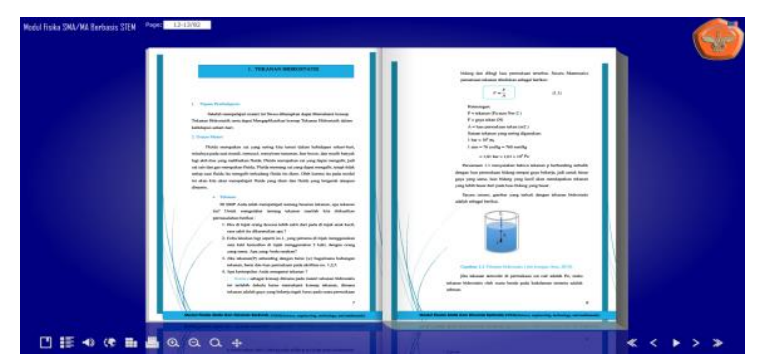
Halaman ini menampilkan halaman awal dan dapat digunakan. dari percobaan yang ada pada e-modul.

d. Tampilan halaman yang menujukkan salah satu dari pendekatan STEM yaitu technology dalam e-modul tersebut.
Tampilan yang menunjukan salah satu technology yang yang ada dalam e-modul

Setelah melakukan design pengembangan e-modul, peneliti melakukan tahap selanjutnya yaitu melakukan tahap pengembangan. Dalam tahap ini dilakukan perbaikan-perbaikan dann kegiatan validasi oleh para validator ahli. Untuk menyesuaikan apa yang dibutuhkan siswa berdasarkan hasil yang diperoleh dari tahapan observasi awal sampai pada tahapan desain. Maka dilakuakn yaitu validasi materi dan validasi media. Validasi tersebut dilakukan oleh dua orang dosen pendidikan fisika Universitas Jambi. Validator akan memberikan saran, kritikan terhadap pengembangan e-modul yang akan dikembangakan. Validasi dilakukan sampai validator menyatakan bahwa pengembangan emodul telah layak digunakan tanpa revisi.

Tahap validasi pertama validator ahli materi menyarankan untuk melengkapi secara detail rumus-rumus yang terdapat didalam emodul serta menambahkan video untuk menambah semangat belajar siswa. Pada tahap kedua validator menyatakan pengembangan emodul telah layak dan dapat digunakan. Selanjutnya yaitu untuk validasi ahli media tahap pertama, validator menyarankan agar tulisan dan jenis huruf disesuaikan dengan software yang digunakan. Menyesuaikan tata letak gambar, dan menyesuaikan warna gambar yang sesuai dengan tema pengembangan emodul. Tahap kedua semua validator menyatakan pengembangan e-modul telah layak

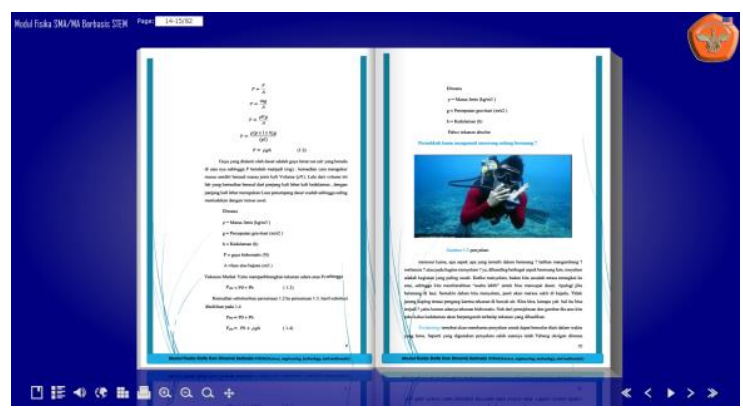




\section{Simpulan}

Berdasarkan hasil pengembangan e-modul dan berdasaarkan hasil validasi maka dihasilkan pengembangan e-modul berbasis STEM ( sains (sicence), teknologi (technology), rekayasa (engineering), and matematika (mathemmatics) pada materi fluida statis dan dinamis menggunakan software kvisooft flipbook maker valid dan layak digunakan. Pengembangan emodul yang telah selesai dikembangakan memiliki format .exe yang dapat dijalankan pada pc/laptop. Pengembangan e-modul ini juga dilengkapi video serta dilengkapi dengan pendekatan STEM dan dapat diakses melalui internet. Pengembangan e-modul ini telah divalidasi dan dinyatakan valid dengan rata-rata skor ahli materi sebesar 3,9 tergolong dalam kategori sangat baik. Dan rata-rata skor ahli media sebesar 3,4 tergolong dalam kategori yang sangat baik.

a. Untuk peneliti selanjutnya rancangan pengembangan e-modul bisa dimodifikasi dengan menambahkan simulasi percobaan menggunakan flash

b. Produk berupa pengembangan pengembangan e-modul berbasis STEM ( sains (sicence), teknologi (technology), rekayasa (engineering), and matematika (mathemmatics) pada materi fluida statis dan dinamis menggunakan software kvisooft flipbook makerdapat di uji coba dilapangan untuk mengetahui kefektifan produk

\section{Daftar Pustaka}

Dewi,A,A. 2019. Buku sebagai bahan ajar. jawa barat :CV jejak.

Ghaliyah, S., Bakri, F., \& Siswoyo. (2015). Pengembangan Modul Elektronik Berbasis Model Laerning Cycle 7E pada Pokok Bahasan Fluida Dinamik untuk Siswa SMA Kelas XI. Prosiding Seminar Nasional Fisika (EJournal) SNF2015, IV.

Hidayati, T.(2018). Pengembangan Perangkat Pembelajaran Matematika Dengan
Suplemen History Of Mathematics. Purwokerto: Cv Pena Persada.

Hidayatullah, M. S., and L.Rakhmawati. "Pengembangan Media Pembelajaran Berbasis Flipbook Maker Pada Mata Pelajaran Elektronika Dasar Di SMK N 1 Sampang." Jurnal Pendidikan Teknik Elektro 5, no. 1 (2016).

Irawan, D, (2020). Mengembangkan Buku Teks Pelajaran Membaca Berbasis Pendekatan Proses Untuk Sd. Puwokerto : Cv Pena Persada.

Irawan, D. 2020. mengembangkan buku teks pelajaran membaca berbasis pendekatan ptoses untuk SD.CV.Pena Persada : Purwokerto Selatan. 